\title{
Purified hepatitis B virus induces human Mesangial cell proliferation and extracellular matrix expression In Vitro
}

\author{
Zongli Diao ${ }^{1+}$, Jiaxiang Ding ${ }^{1 \dagger}$, Chenghong Yin², Liyan Wang ${ }^{1}$ and Wenhu Liu ${ }^{1 *}$
}

\begin{abstract}
Background: Hepatitis B virus (HBV) induces proliferation of human mesangial cells (HMCs), and extracellular matrix expression through the deposition of immune complexes in renal tissue. However, it is unclear whether HBV can directly affect HMCs. In this study, the effects of purified HBV on HMC proliferation and extracellular matrix expression in vitro was determined.
\end{abstract}

Findings: HBV was purified using sucrose density gradient centrifugation. HMCs were co-cultured with purified HBV $\left(10^{4}-10^{6}\right.$ copies $\left./ \mathrm{ml}\right)$ for $48 \mathrm{~h}$, and cell proliferation determined using 5-ethynyl-2'-deoxyuridine immunofluorescence assays. After HMCs were co-cultured with $10^{6}$ copies/ml purified HBV for 0, 12, 24, 36 and 48 h, expression of type IV collagen and fibronectin was measured using enzyme-linked immunosorbent assays. Three titers of purified HBV $\left(10^{4}, 10^{5}\right.$, and $10^{6}$ copies $\left./ \mathrm{ml}\right)$ induced HMC proliferation, with the proportion of increases in cell numbers at $24.7 \pm$ $4.3,31.2 \pm 9.4$, and $36.8 \pm 7.5 \%$, respectively. All these increases were significantly higher than those for the control group (13.6 $\pm 4.2 \%$ ) (All $p<0.05)$. Purified HBV $\left(10^{6} \mathrm{copies} / \mathrm{ml}\right)$ significantly increased the levels of type IV collagen and fibronectin in supernatants compared with the control group at 12 and $48 \mathrm{~h}$ (All $p<0.05$ ).

Conclusions: Purified HBV can directly promote HMC proliferation and expression of type IV collagen and fibronectin, and could be involved in the pathogenesis of HBV-associated glomerulonephritis.

Keywords: Hepatitis B virus, Human mesangial cells, Proliferation, Type IV collagen, Fibronectin

\section{Introduction}

Hepatitis B virus (HBV) infections are prevalent in China [1], and infection with this virus can result in the development of HBV-associated glomerulonephritis (HBV-GN). HBV-GN has become a prevalent type of secondary glomerulonephritis in China [2]. Human mesangial cell (HMC) proliferation and increases in the expression of extracellular matrix proteins, including type IV collagen and fibronectin (FN), were involved in various pathological types of HBV-GN. The most common pathological type of HBV-GN is HBV-associated membranous nephropathy (HBV-MN). Proliferation of HMCs, and increases in extracellular matrix protein levels are more common in HBV-MN compared with the idiopathic form [3].

\footnotetext{
*Correspondence: liuwenhu2013@163.com

'Equal contributors

'Department of Nephrology, Beijing Friendship Hospital, Capital Medical University, 95 Yong-An Road, Beijing 100050, China

Full list of author information is available at the end of the article
}

Additionally, HMC proliferation and increases in extracellular matrix protein expression are common in other pathological types of HBV-GN such as membranoproliferative glomerulonephritis.

The most widely accepted mechanism for increases in HMC proliferation, and expression levels of extracellular matrix proteins in HBV-GN is through the deposition of HBV immune complexes [4]. Many studies have shown that expression of HBV DNA in glomeruli suggests direct viral-induced pathological alterations of HMC could contribute to the pathogenesis of HBV-GN $[5,6]$. The main effect of HBV DNA in renal tissues on HMCs was because of $\mathrm{HBV}$ antigens (HBAg) and HBV antibodies (HBAb) forming immune complexes in situ [5,7]. It remains unclear whether HBV can directly affect HMCs; therefore, in this study we purified HBV virons and subviral particles from the serum of $\mathrm{HBV}$-infected patients, and investigated the effects of purified HBV on HMC

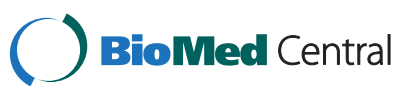



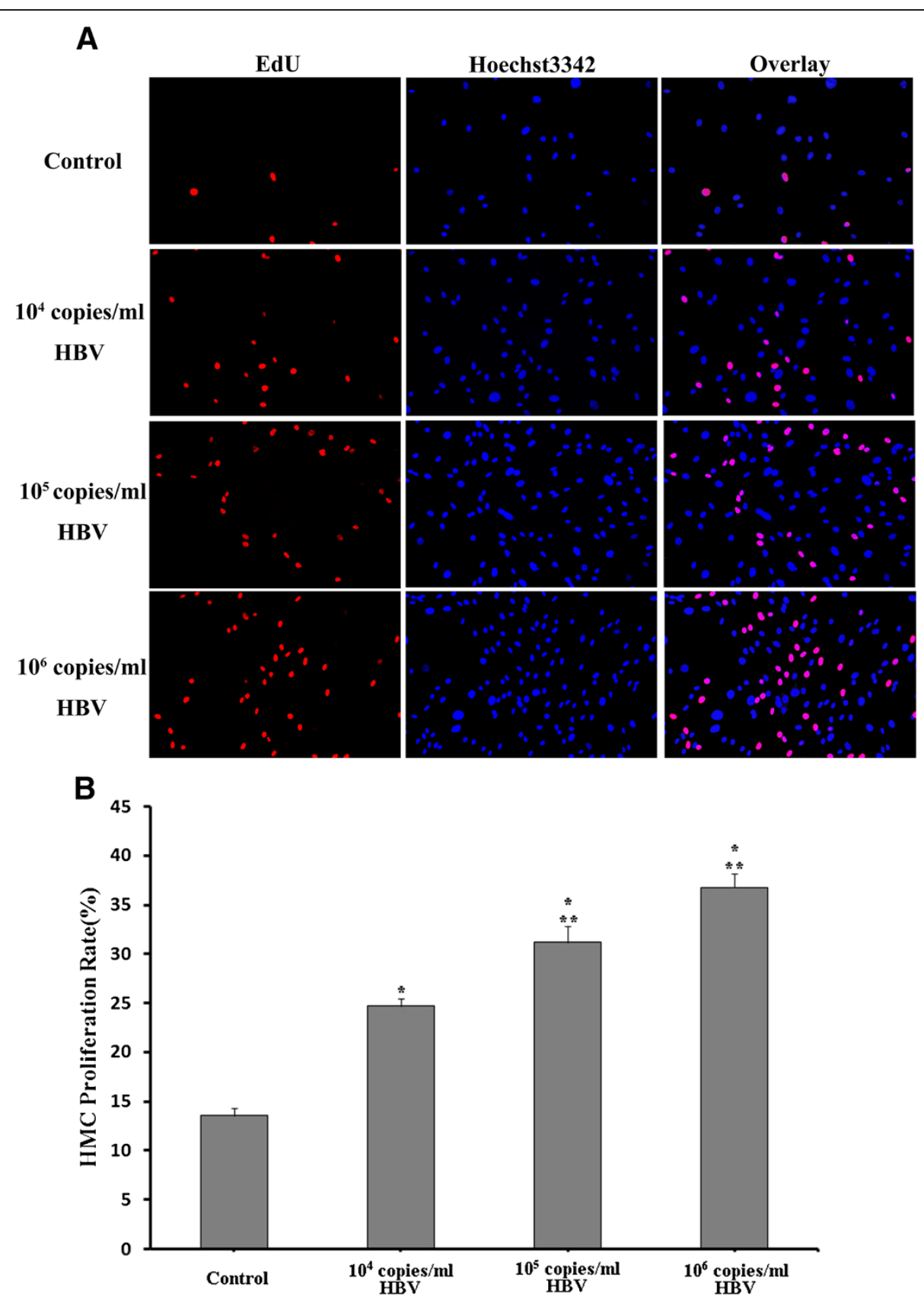

Figure 1 Various titers of HBV can induce HMC proliferation after $\mathbf{4 8}$ h. (A) Detection of EdU (left) and Hoechst3342 (center) incorporation in cultured HMCs, and overlay images (right). (B) HMC proliferation in control and HBV co-culture groups. ${ }^{* *} p<0.05$ compared with that in normal MsCM. ${ }^{* *} p<0.05$ compared with that in MsCM containing $10^{4}$ copies $/ \mathrm{ml} \mathrm{HBV}$. Results are presented as means \pm SEM.

proliferation, and on the expression levels of type IV collagen and FN.

\section{Methods}

Isolation and purification of HBV

We isolated HBV from the HBV DNA-positive sera of chronic HBV patients, in our hospital, containing more than $5.0 \times 10^{8}$ copies $/ \mathrm{ml}$ of circulating HBV. Virus was purified by sucrose density gradient centrifugation as previously described [8].

\section{Cell culture and cell proliferation assays}

HMCs (ScienCell, San Diego, CA, USA) were cultured in Mesangial Cell Medium (MsCM; ScienCell, Carlsbad, USA) at $37^{\circ} \mathrm{C} / 5 \% \mathrm{CO}_{2}$. Cells were seeded into 12 -well culture plates at a density of $1.0 \times 10^{4}$ cells/well and 
incubated for $24 \mathrm{~h}$ in RPMI 1640 medium. We then applied HBV at various doses $\left(10^{4}, 10^{5}\right.$, and $10^{6}$ copies $\left./ \mathrm{ml}\right)$ to $\mathrm{HMC}$ cultures. At $48 \mathrm{~h}$ post-seeding, cell proliferation was determined using 5-ethynyl-2'-deoxyuridine (EdU) immunofluorescence assays according to the manufacturer's instructions (Ribobio, Guangzhou, Guangdong, China). The culture medium was replaced with normal MsCM containing $50 \mu \mathrm{M}$ EdU. After a 3-h incubation, cells were fixed with formaldehyde. After washing with phosphate-buffered saline (PBS) containing 0.5\% Triton $\mathrm{X}-100$, cells were washed with PBS and counterstained with Hoechst 33342. Cells were visualized by fluorescence microscopy and using Image-Pro Plus 6.0 (Media Cybernetics, Rockville, MD, USA). The level of HMC proliferation was determined using the following formula:

$\mathrm{HMC}$ proliferation $=($ number of EdU-positive cells/all cells $)$ $\times 100$.

\section{Enzyme-linked immunosorbent assays (ELISAs)}

Cells were seeded into 12-well culture plates at a density of $1.0 \times 10^{4}$ cells/well and incubated for $24 \mathrm{~h}$ in normal RPMI 1640 medium. We then applied MsCM alone, or $10^{6}$ copies/ml of HBV in MsCM. At $0,12,24,36$, and $48 \mathrm{~h}$ post-seeding, the supernatants of each well were collected, and type IV collagen and FN levels measured by ELISA according to the manufacturer's instructions (Blue-gene, Shanghai, China).

\section{Statistical analysis}

All data were expressed as the mean \pm the standard error of the mean (SEM). Statistical analysis was carried out using Tamhane's T2 test for HMC proliferation, and the Independent-Samples $T$-test for type IV collagen and FN. Differences were considered significant when the $P$-value was less than 0.05 . All results were repeated for three times.

\section{Results}

\section{HMC Proliferation}

Proliferation of HMCs in control, $10^{4}, 10^{5}$, and $10^{6}$ copies $/ \mathrm{ml} \mathrm{HBV-infected} \mathrm{cultures} \mathrm{were} \mathrm{increased} \mathrm{by} 13.6 \pm$ $4.1,24.7 \pm 4.3,31.2 \pm 9.4$, and $36.8 \pm 7.5 \%$, respectively (Figure 1).

\section{Extracellular matrix protein levels}

Using $10^{6}$ copies/ml HBV significantly increased the expression levels of type IV collagen and FN in HMCs $(p<0.05$; Figure 2).

\section{Discussion}

In our study, we found that purified HBV significantly increased HMC proliferation, and also increased expression levels of type IV collagen and FN. The major mechanism of increased HMC proliferation and extracellular matrix expression in HBV-GN is suggested to be due to HBV immune complex deposition [6,9]. However, many studies have detected HBV DNA, as both free and integrated forms, in mesangial cells. He et al. have reported that the expression of HBV DNA in the nucleus and cytoplasm of HMCs in HBV-GN patients verified the presence of HBV DNA in HMC [5]. Wang et al. showed that HBV DNA as the integrated form was detected in $82 \%(41 / 50)$ of cases in HMCs by in situ hybridization [7]. These observations suggest that HBV DNA can infect HMCs, and that it can directly induce pathological alterations in HMCs that might be involved in HBV-GN [10]. However, these studies were all conducted in renal tissues, and the effects of HBV on HMCs were suggested to be a result of immune complex formation in situ $[7,11]$. Because of confounding factors involving immune complexes that are circulating, it was difficult to show whether HBV can directly affect HMCs in these studies. In our study, we purified HBV from the sera of HBV-infected patients. The HMCs were co-cultured with purified HBV in vitro, thereby overcoming the confounding factors

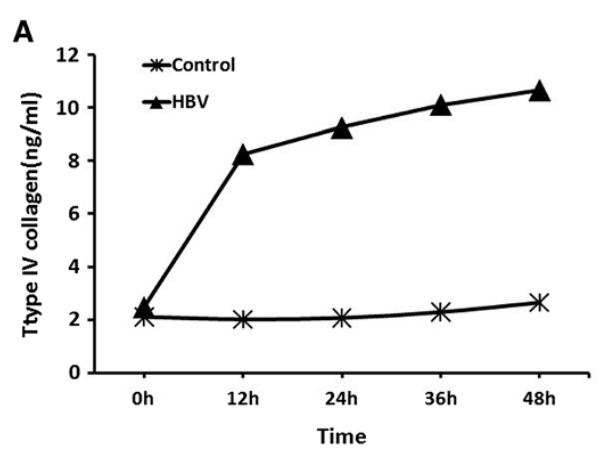

B

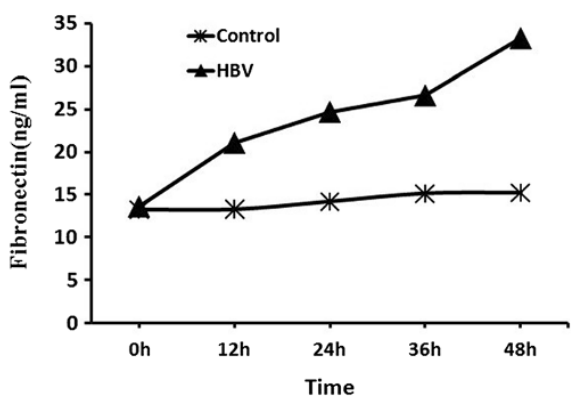

Figure 2 HMCs were co-cultured with purified HBV. Type IV collagen (A) and FN (B) levels in supernatants increased significantly compared with controls at $12,24,36$, and $48 \mathrm{~h}(p<0.05)$. 
related to the immune complex, and we showed that purified HBV directly affected HMCs.

There were some limitations to our study. We did not explore the mechanisms through which HBV increased HMC proliferation and expression of extracellular matrix proteins. $\mathrm{HBV} \mathrm{X}$ Protein $(\mathrm{HBx})$ acts an indirect transcriptional transactivitor to regulate cell proliferation, transdifferentiation and apoptosis [12]. Some studies have shown that $\mathrm{HBx}$ can induce mesangial cell proliferation through the upregulation of interleukin-1 $\beta$ and interleukin-6 [13]. However, in these previous studies, $\mathrm{HBx}$ was transfected into mesangial cells artificially; therefore, it remains unknown whether HBV can induce HMC proliferation through a natural infection. Further studies will be required to clarify this.

In conclusion, our findings support the hypothesis that HBV exerts direct effects on HMCs, and will hopefully enrich our understanding of the pathogenesis of HBV-GN.

\section{Abbreviations}

EdU: 5-ethynyl-2'-deoxyuridine; ELISA: Enzyme-linked immunosorbent assay; FN: Fibronectin; HBV: Hepatitis B virus; HBV-GN: HBV-associated glomerulonephritis; HBV-MN: HBV-associated membranous nephropathy; HBx: HBV X protein; HMC: Human mesangial cells; MsCM: Mesangial cell medium.

\section{Competing interests}

The authors declare that they have no competing interests.

\section{Authors' contributions}

DZ and JD carried out all experiments in this study, collated the information, performed the literature search and drafted the manuscript. CY performed the EdU assays. LW performed the ELISA experiments. WL, the corresponding author, designed the research project, performed the literature search and prepared the manuscript. All authors read and approved the final manuscript.

\section{Acknowledgments}

This work was supported by Starting Foundation of Beijing Friendship Hospital, Capital Medical University (201007), Beijing Municipal Science and Technology Commission Funds (D131100004713001).

\section{Author details}

'Department of Nephrology, Beijing Friendship Hospital, Capital Medical University, 95 Yong-An Road, Beijing 100050, China. ${ }^{2}$ Department of Infectious Disease, Beijing Friendship Hospital, Capital Medical University, 95 Yong-An Road, Beijing 100050, China.

Received: 1 August 2013 Accepted: 30 September 2013 Published: 4 October 2013

\section{References}

1. Tanaka M, Katayama F, Kato H, Tanaka H, Wang J, Qiao YL, Inoue M: Hepatitis $B$ and $C$ virus infection and hepatocellular carcinoma in China: a review of epidemiology and control measures. J Epidemiol 2011, 21:401-416

2. $\quad X u H$, Sun L, Zhou LJ, Fang LJ, Sheng FY, Guo YQ: The effect of hepatitis B vaccination on the incidence of childhood $\mathrm{HBV}$-associated nephritis. Pediatr Nephrol 2003, 18:1216-1219.

3. Li P, Wei RB, Tang L, Wu J, Zhang XG, Chen XM: Clinical and pathological analysis of hepatitis $B$ virus-related membranous nephropathy and idiopathic membranous nephropathy. Clin Nephrol 2012, 78:456-464.
4. Takekoshi $Y$, Tochimaru H, Nagata $Y$, Itami N: Immunopathogenetic mechanisms of hepatitis B virus-related glomerulopathy. Kidney Int 1991, 35(Suppl):34-39.

5. He XY, Fang LJ, Zhang YE, Sheng FY, Zhang XR, Guo MY: In situ hybridization of hepatitis B DNA in hepatitis B-associated glomerulonephritis. Pediatr Nephrol 1998, 12:117-120.

6. Lai KN, Ho RT, Tam JS, Lai FM: Detection of hepatitis B virus DNA and RNA in kidneys of HBV related glomerulonephritis. Kidney Int 1996, 50:1965-1977.

7. Wang NS, Wu ZL, Zhang YE, Liao LT: Existence and significance of hepatitis B virus DNA in kidneys of IgA nephropathy. World J Gastroenterol 2005, 11:712-716.

8. Glebe D, Urban S, Knoop EV, Cag N, Krass P, Grun S, Bulavaite A, Sasnauskas K, Gerlich WH: Mapping of the hepatitis B virus attachment site by use of infection-inhibiting preS1 lipopeptides and tupaia hepatocytes. Gastroenterology 2005, 129:234-245.

9. Appel GB: Immune-complex glomerulonephritis-deposits plus interest. N Engl J Med 1993, 328:505-506.

10. Chen L, Wu C, Fan X, Gao J, Yin H, Wang T, Wu J, Wen SW: Replication and infectivity of hepatitis B virus in HBV-related glomerulonephritis. Int J Infect Dis 2009, 13:394-398.

11. Wang NS, Wu ZL, Zhang YE, Guo MY, Liao LT: Role of hepatitis B virus infection in pathogenesis of IgA nephropathy. World J Gastroenterol 2003, 9:2004-2008.

12. $\mathrm{Ng}$ SA, Lee $\mathrm{C}$ : Hepatitis $B$ virus $X$ gene and hepatocarcinogenesis. J Gastroenterol 2011, 46:974-990.

13. Lu H, Zhou J: HBV X gene transfection upregulates IL-1beta and IL-6 gene expression and induces rat glomerular mesangial cell proliferation. J Huazhong Univ Sci Technolog Med Sci 2008, 28:247-250.

doi:10.1186/1743-422X-10-300

Cite this article as: Diao et al.: Purified hepatitis B virus induces human Mesangial cell proliferation and extracellular matrix expression In Vitro. Virology Journal 2013 10:300.

\section{Submit your next manuscript to BioMed Central and take full advantage of:}

- Convenient online submission

- Thorough peer review

- No space constraints or color figure charges

- Immediate publication on acceptance

- Inclusion in PubMed, CAS, Scopus and Google Scholar

- Research which is freely available for redistribution 